\title{
Total Homocysteine, Folate, and Cobalamin, and Their Relation to Genetic Polymorphisms, Lifestyle and Body Mass Index in Healthy Children and Adolescents
}

\author{
MARTINA HUEMER, KURT VONBLON, MANUELA FÖDINGER, RUTH KRUMPHOLZ, MICHAEL HUBMANN, \\ HANNO ULMER, AND BURKHARD SIMMA
}

\begin{abstract}
Departments of Pediatrics [M.H., K.V., B.S.], Anesthesia [R.K.], and Laboratory Medicine [M.H.], Academic Teaching Hospital Landeskrankenhaus (LKH), 6800 Feldkirch, Austria; Clinical Institute of Medical and Chemical Laboratory Diagnostics [M.F.], Vienna Medical School, 1090 Vienna, Austria; Department of Medical Statistics [H.U.], Informatics and Health Economics, Innsbruck Medical University, 6020 Innsbruck, Austria
\end{abstract}

\begin{abstract}
We investigated total homocysteine (tHcy) concentrations and relations between tHcy and folate, cobalamin $(\mathrm{Cbl})$, genetic polymorphisms (MTHFR $677 \mathrm{C}>\mathrm{T}$, MTHFR $1298 \mathrm{~A}>\mathrm{C}$, MTHFR $1793 \mathrm{G}>\mathrm{A}$ ), blood pressure (BP), body mass index (BMI), cholesterol, triglycerides, sports activities, family and individual history of cardiovascular disease (CVD) and lifestyle issues in 264 healthy children and adolescents (2-17 y). THcy concentrations significantly increased while folate and $\mathrm{Cbl}$ decreased with age without gender differences. Age, folate and $\mathrm{Cbl}$ were significant predictors for tHcy concentrations. THcy was higher but within normal ranges in MTHFR 677TT homozygotes $(10.6 \%)$ and carriers of the MTHFR 1793 A allele $(8 \%)$. Only two individuals $(0.8 \%)$, both with low tHcy concentrations, were homozygous for MTHFR 1793AA. THcy concentration correlated positively with creatinine, triglycerides, BMI and systolic BP and was not related to cholesterol, sports activities and family history of CVD.

In conclusion, tHcy concentrations in this pediatric population were significantly influenced by age, folate and $\mathrm{Cbl}$ concentrations. No gender differences for tHcy, folate or Cbl concentrations were observed. Both the MTHFR 677TT genotype and the MTHFR 1793A allele were not associated with hyperhomocysteinemia. The prevalence of the MTHFR 1793AA genotype was too low for meaningful interpretation. (Pediatr Res 60: 764-769, 2006)
\end{abstract}

$\mathrm{T}$ he sulfur containing amino acid homocysteine (Hcy) takes an integral part in the de- and remethylation of methionine (1). Hyperhomocysteinemia is an independent risk factor for thrombosis, premature vasculopathy, stroke, atherosclerosis, eclampsia, abortion and neural tube defects in offspring $(2,3)$, and correlates with reduced cognitive performance in the elderly (4). In childhood, tHcy concentrations exceeding the $95^{\text {th }}$ percentile of the age-corrected distribution are related to a 4-fold increased risk for ischemic cerebrovascular disease (5).

Severe hyperhomocysteinemia is mostly caused by rare inborn errors of metabolism (cystathion- $\beta$-synthase defi-

Received February 22, 2006; accepted July 19, 2006.

Correspondence: Martina Huemer, M.D., Landeskrankenhaus Feldkirch, Department of Pediatrics, Carinagasse 47, 6800 Feldkirch, Austria; E-mail: martina@huemerlindau.de

Supported by a grant from SHS Clinical Nutrition, Heilbronn, Germany.

DOI: $10.1203 / 01 . p d r .0000246099 .39469 .18$ ciency, methylenetetrahydrofolate reductase [MTHFR] deficiency, inborn errors of cobalamin $[\mathrm{Cbl}]$ metabolism) $(5,6)$. The much more frequent mild to moderate $(10-30 \mu \mathrm{mol} / \mathrm{L})$ fasting hyperhomocysteinemia in adults (7) can be caused by deficiency of cofactors essential to Hcy metabolism - predominantly folate and $\mathrm{Cbl}$ - by polymorphisms in genes coding for enzymes involved in the Hcy pathway and by exogenous factors $(6,8)$. Exogenous factors include obesity, physical inactivity, specific medications (e.g. anticonvulsants, folate antagonists), chronic inflammatory disease, hypothyroidism, smoking and frequent intake of coffee or alcohol (8). Some of these exogenous factors may in fact cause hyperhomocysteinemia via cofactor depletion. In general tHcy concentrations increase with age and are higher in males and postmenopausal women (8).

In adults, the MTHFR 677TT and the compound heterozygous MTHFR 677T/1298C genotypes are associated with hyperhomocysteinemia and cardiovascular disease $(2,3)$. The impact of the recently described MTHFR $1793 \mathrm{G}>$ A polymorphism $(9,10)$ on tHcy concentrations has currently only been studied in specific populations of adult individuals but not in children (11).

In healthy children and adolescents, tHcy concentration has been investigated in a very limited number of studies in several ethnic groups with divergent age distribution using different statistical models. The cut offs categorizing normoand hyperhomocysteinemia derived from these studies cover the range from 8.3-11.3 $\mu \mathrm{moL}(12-14)$ and make the definition of hyperhomocysteinemia in children and adolescents a difficult task. Moreover, the impact of genetic polymorphisms, vitamin concentrations and exogenous factors on tHcy in children has not yet been studied in detail. Since safe and cost effective strategies for prevention and treatment of hyperhomocysteinemia are well established $(7,15)$, the present study is

Abbreviations: BP, blood pressure; Cbl, cobalamin; CVD, cardiovascular disease; Hcy, homocysteine; MTHFR, methylene tetrahydrofolate reductase; tHcy, total homocysteine 
Table 1. Age adjusted means, standard deviations (SD) and ranges for tHcy, folate and Cbl according to gender, ethnic background, history of CVD in first grade relatives, sports activities in scholars, onset of menstruation in females

\begin{tabular}{|c|c|c|c|c|c|c|c|c|c|c|}
\hline & \multirow[b]{2}{*}{$\mathrm{N}$} & \multicolumn{3}{|c|}{ tHcy } & \multicolumn{3}{|c|}{ Folate } & \multicolumn{3}{|c|}{$\mathrm{Cbl}$} \\
\hline & & Mean & SD & Range & Mean & SD & Range & Mean & SD & Range \\
\hline Gender* & 264 & & & & & & & & & \\
\hline Males & 132 & 6.5 & 1.1 & $3.1-13.1$ & 9.2 & 1.5 & $3.3-16.7$ & 508 & 77 & $160-1,345$ \\
\hline Females & 132 & 6.6 & 1.1 & $3.5-18.6$ & 9 & 1.5 & $2.5-19.2$ & 500 & 79 & $142-1,050$ \\
\hline Turkish & 56 & 6.2 & 1 & $3.7-10.9$ & 9.6 & 1.4 & $4-16.1$ & 529 & 70 & $163-1,328$ \\
\hline Others & 10 & 5.9 & 1.1 & $4.3-18.6$ & 10 & 1.5 & $6.2-17.5$ & 549 & 80 & $201-1,102$ \\
\hline Family history CVD* & 223 & & & & & & & & & \\
\hline Yes & 8 & 6 & 0.8 & $3.8-7.1$ & 9.9 & 1.1 & $5.1-17.5$ & 545 & 58 & $401-731$ \\
\hline No & 215 & 6.6 & 1.1 & $3.1-13.9$ & 9.1 & 1.5 & $2.5-19.2$ & 506 & 78 & $163-1,328$ \\
\hline $\begin{array}{l}\text { Sports activities* } \\
\text { (school children) }\end{array}$ & 146 & & & & & & & & & \\
\hline Menstruation* & 132 & & & & & & & & & \\
\hline Yes & 25 & 8.2 & 0.6 & $4.2-13.9$ & 6.8 & 0.8 & $3.5-15.1$ & 387 & 39 & $183-590$ \\
\hline No & 107 & 6.1 & 0.7 & $3.5-18.6$ & 9.8 & 1 & $2.5-19.2$ & 540 & 50 & $163-1,050$ \\
\hline
\end{tabular}

* ANOVA $p$-value $>0.05$.

Table 2. Percentiles (5 $5^{\text {th }}[\mathrm{P5}]$ and $\left.95^{\text {th }}[\mathrm{P95}]\right)$ for tHcy, folate and Cbl in children and adolescents from 2-17 yrs

\begin{tabular}{|c|c|c|c|c|c|c|c|c|c|c|c|c|c|c|c|c|}
\hline & \multirow{2}{*}{$\begin{array}{c}\mathrm{N} \\
264\end{array}$} & \multicolumn{5}{|c|}{ tHcy* $(\mu \mathrm{mol} / \mathrm{L})$} & \multicolumn{5}{|c|}{ Folate* (ng/mL) } & \multicolumn{5}{|c|}{$\mathrm{Cb} 1^{*}(\mathrm{pg} / \mathrm{mL})$} \\
\hline & & Mean & SD & Range & P5 & P95 & Mean & SD & Range & P5 & P95 & Mean & SD & Range & P5 & P95 \\
\hline $6-9$ years & 77 & 6.2 & 1.9 & $3.5-18.6$ & 4.2 & 9.2 & 10.7 & 3.1 & $3.6-16.7$ & 4.8 & 16.2 & 559 & 207 & 201-1050 & 250 & 947 \\
\hline $10-13$ years & 50 & 7.3 & 1.9 & $3.1-13.1$ & 4.3 & 11.9 & 7.7 & 3.2 & $3.3-15.1$ & 3.7 & 13.8 & 437 & 178 & $163-889$ & 201 & 837 \\
\hline $14-17$ years & 47 & 8.6 & 2.3 & $4.2-13.9$ & 4.7 & 12.8 & 6.3 & 2.6 & $3.5-15.1$ & 3.6 & 12.3 & 355 & 134 & $142-736$ & 159 & 650 \\
\hline
\end{tabular}

$* p<0.0001$ for ANOVA differences between age groups.

aimed at investigating tHcy, defining hyperhomocysteinemia and identifying factors influencing tHcy concentrations in a pediatric population. Therefore genetic polymorphisms, folate, Cbl, body mass index (BMI), blood pressure (BP), cholesterol, triglycerides, creatinine and lifestyle factors were investigated in a population of 264 young individuals.

\section{METHODS}

The study was approved by the ethics committee of the Leopold Franzens University, Innsbruck, Austria. Informed consent/assent was obtained from all participants $>8 \mathrm{y}$ and their parents/guardians. Venous puncture was conducted for independent medical reasons.

Subjects. Two hundred sixty-four children and adolescents age 2-17 yrs admitted for elective surgery (adenotonsillectomy, tympanostomy tube insertion, removal of metal devices, orthopedic or eye surgery), radiologic procedures (magnetic resonance imaging) or allergy testing to the Landeskrankenhaus Feldkirch (Austria) were recruited. None of the participants received vitamin supplements or any other drugs on a regular basis or had clinical evidence of acute infection, renal dysfunction, hypothyroidism, chronic inflammatory disease, inborn errors of $\mathrm{Hcy}, \mathrm{Cbl}$ or folate metabolism or any other condition known to be associated with an increase or decrease in tHcy at the time of sample collection.

Parameters. Using a standardized data sheet, age, sex, ethnic background, family (first-degree relatives) and individual histories of CVD, date of onset of menstruation and intake of oral contraceptives were recorded. Time spent on sports activities/week, e.g. in a sports club (categories: none, $1-3 \mathrm{~h},>3 \mathrm{~h}$ ) was asked for in school-age children, because structured sports activity is unusually not attended by preschool children. Weight and height were mea- sured using a standardized setting. The BMI was calculated using the formula (weight/height $\left[\mathrm{kg} / \mathrm{m}^{2}\right]$ ). Blood pressure was measured according to the Riva-Rocci method. THcy, folate, $\mathrm{Cbl}$ and the MTHFR polymorphisms $677 \mathrm{C}>\mathrm{T}, 1298 \mathrm{~A}>\mathrm{C}$ and $1793 \mathrm{G}>\mathrm{A}$ were assessed from a $6-\mathrm{mL}$ blood sample taken after an overnight fast. Plasma tHcy concentrations were determined using an automated fluorescence polarization immunoassay (FPIA, Abbott $\mathrm{IMx}^{\circledR}$ analyzer). $\mathrm{Cbl}$ and folate concentrations were measured in serum with a Microparticle Enzyme Immunoassay (Abbott Imx ${ }^{\circledR}$ Analyzer, Abbott Laboratories, Abbott Park, IL). For analysis of the genetic polymorphisms, genomic DNA was isolated from citrated blood samples according to standard procedures. Identification of MTHFR $677 \mathrm{C}>\mathrm{T}, M T H F R \quad 1298 \mathrm{~A}>\mathrm{C}$, and MTHFR $1793 \mathrm{G}>\mathrm{A}$ was performed as described (11). Serum creatinine, triglycerides, and cholesterol concentrations were measured at $37^{\circ} \mathrm{C}$ using standard laboratory assays.

Statistical analysis. Age-specific percentiles of tHcy, folate and $\mathrm{Cbl}$ were calculated to describe the distribution of these parameters with increasing age. For different characteristics of the population, age-adjusted means are presented. For the polymorphisms under study, allelic frequencies were calculated using the equations $\mathrm{p}=[2 \mathrm{n}$ (wild type/wild type $)+\mathrm{n}$ (wild type/mutated type) $] / 2 \mathrm{~N}$ for the wild type allele and $\mathrm{q}=[\mathrm{n}$ (wild type/mutated type $)+2 \mathrm{n}$ (mutated type/mutated type)]/2 $\mathrm{N}$ for the mutated allele. Genotypic frequencies of each polymorphism were calculated using the equations $\mathrm{D}=\mathrm{n}$ (wild type/wild type)/N; $\mathrm{H}=\mathrm{n}$ (wild type/mutated type)/N and $\mathrm{R}=\mathrm{n}$ (mutated type/mutated type)/N. The Hardy-Weinberg equilibrium was calculated for each polymorphism and the $\chi^{2}$ test was used to test for deviation of the observed genotype frequencies from Hardy-Weinberg expectations. Pearson correlation coefficients were used to assess the relation between tHcy, folate and $\mathrm{Cbl}$ and other measurements. Analysis of variance (ANOVA) was used univariately to test effects of age groups, gender, ethnic background, family history of CVD, categories for sports activities, menstruation and genetic polymorphisms on tHcy, folate and Cbl. Finally, linear multiple regression 
Table 3. Distribution of genetic polymorphisms, ratio of observed cases to Hardy-Weinberg expectations and impact of different genotypes on tHcy, folate and Cbl concentrations

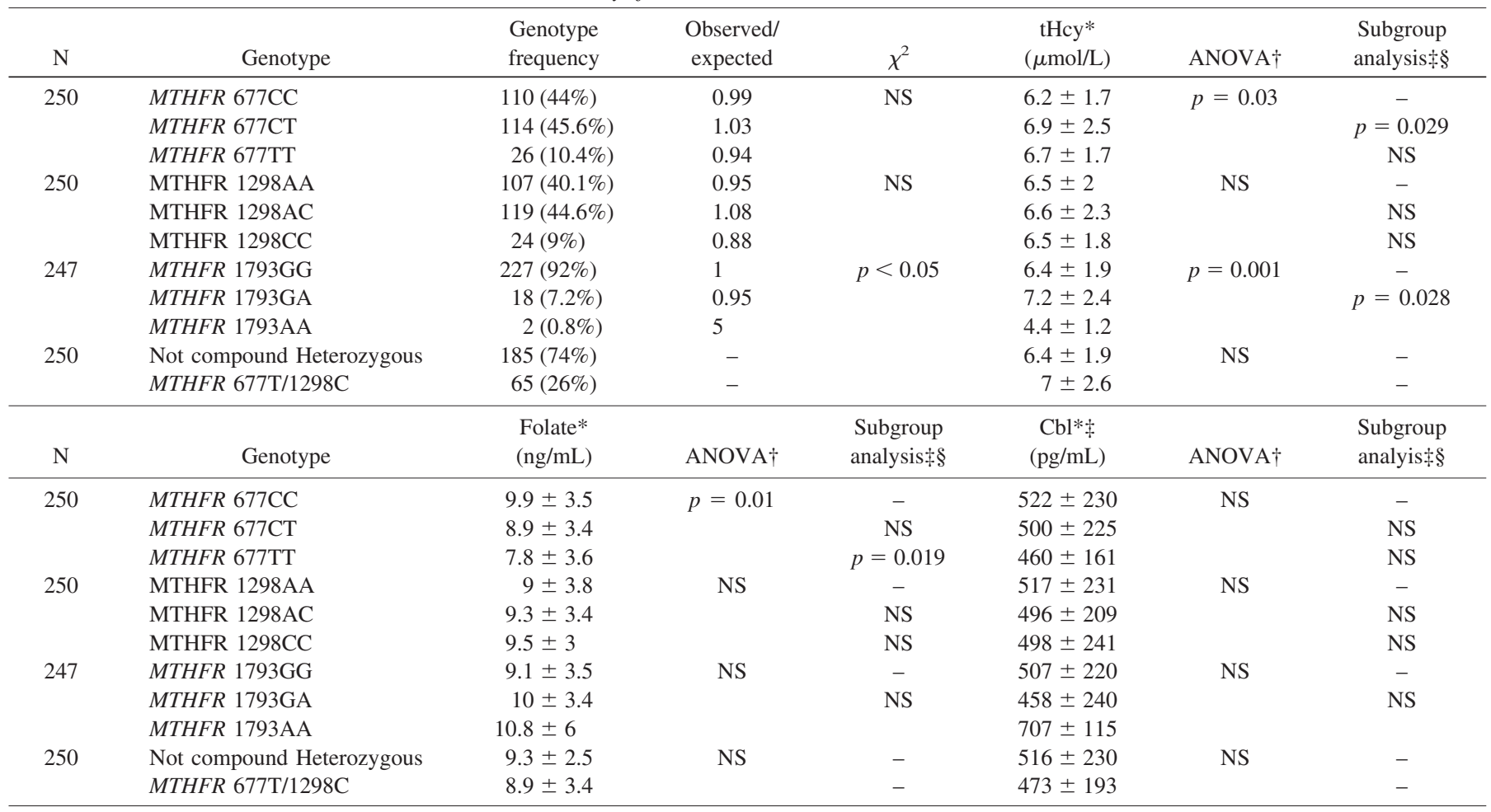

* Means \pm SD.

$\dagger$ ANOVA testing wild type versus mutated genotypes.

$\ddagger$ Bonferroni corrected subgroup analysis comparing wild type versus heterozygotes and wild type versus homozygotes for MTHFR $677 \mathrm{C}>\mathrm{T}$ and $M T H F R$ $12898 \mathrm{~A}>\mathrm{C}$.

$\S$ Bonferroni corrected subgroup analysis comparing wild type versus heterozygotes and homozygotes for MTHFR $1793 \mathrm{G}>\mathrm{A}$.

NS, not significant.

analyses in different age groups were performed to evaluate independent predictors for tHcy. Besides the above mentioned variables, BP, BMI, cholesterol, triglycerides and creatinine were included. Only variables significantly predicting tHcy are reported in the final models. Application of parametric methods was justified since variables were approximately normally distributed. $P$ values $<0.05$ were considered statistically significant.

\section{RESULTS}

Two hundred sixty-four children and adolescents (132 females, 132 males) participated in the study. Ninety participants were between 2 and 5 yrs, 77 between 6 and 9 yrs, 50 between 10 and $13 \mathrm{yrs}$ and 47 between 14 and 17 yrs old. None of the participants had an individual history of CVD. A positive family history for CVD among first-degree relatives was present in 8 (3\%), nonexistent in 215 and unknown in 41 participants. One hundred seventy-four children older than $5 \mathrm{y}$ were asked about their engagement in sports activities (hours per week). Twenty-eight children/parents were unable to estimate the child's sports activities according to the given categories, therefore data from 146 school children were included in the analysis. Twenty-five out of 132 female participants were after the onset of menstruation. Only $1.5 \%$ of the participants reported to be smokers and $1.7 \%$ of the females took oral contraceptives. Therefore the impact of both parameters on tHcy cannot be estimated.

No significant differences concerning tHcy, folate and $\mathrm{Cbl}$ concentrations were present between males and females, eth- nic groups, engagement in sports activities in school children or between participants with or without a family history of CVD. In females, postmenarchal status was associated with higher tHcy, lower folate and lower Cbl concentrations (all $p<0.001$, data not shown), but after correction for age these effects were no longer significant (table 1).

tHcy concentrations increased while folate and $\mathrm{Cbl}$ concentrations decreased significantly with age (all $p<0.001$ ) (Table 2). Genetic polymorphisms interfering with Hcy metabolism were investigated in 250/264 (MTHFR 677C > T, MTHFR 1298A $>$ C) and 247/264 (MTHFR 1793G $>$ A) participants respectively (Table 3 ). In the remaining subjects, polymorphisms were not assessable due to blood sample collection problems. Both the MTHFR $677 \mathrm{C}>\mathrm{T}$ and the MTHFR $1298 \mathrm{~A}>\mathrm{C}$ polymorphism, showed allele frequencies of 0.67 for the wild type and 0.33 for the mutated allele. No significant deviations from Hardy-Weinberg expectations were present. The MTHFR 677T allele was significantly associated with higher tHcy and lower folate concentrations both in ANOVA and in Bonferroni corrected subgroup analysis and showed no significant impact on $\mathrm{Cbl}$ concentrations. Nevertheless, tHcy concentrations were within normal ranges. No interaction between low folate or Cbl levels and the MTHFR 677TT genotype with respect to tHcy was present $(p=0.34$ and 0.2 respectively, data not shown). No significant impact on tHcy, folate or $\mathrm{Cbl}$ concentrations was present 
for the MTHFR $1298 \mathrm{~A}>\mathrm{C}$ polymorphism and the compound heterozygous MTHFR 1298C/677T genotype. For MTHFR $1793 \mathrm{G}>\mathrm{A}$, allele frequencies were 0.96 for the wild type and 0.04 for the mutated allele, and in this case, deviations from Hardy-Weinberg expectations were significant $\left(p \leq 0.05, \chi^{2}\right)$. Due to the small sample size of the MTHFR 1793AA genotype Bonferroni corrected subgroup analysis was conducted comparing the wild type versus the two mutated genotypes (MTHFR 1793AA and MTHFR 1793GA). tHcy was significantly higher in carriers of at least one mutated allele but interestingly the 2 individuals carrying the MTHFR 1793AA genotype had low tHcy concentrations $\left(<3^{\text {rd }}\right.$ and $<10^{\text {th }}$ percentile, data not shown) but due to the small sample size the validity of this result cannot be estimated.

Linear multiple regression analyses with tHcy as the dependent variable were conducted separately for children $>5 \mathrm{y}$ of age and in younger children because in the latter group the hours of sports activities per week had not been investigated. In children $>5 \mathrm{y}$, age, folate, $\mathrm{Cbl}$ and the MTHFR 1793A allele were significant predictors of tHcy on linear regression analysis (Table 4). All other parameters did not reach significance. In the younger children only $\mathrm{Cbl}$ and folate were significant (Table 4).

Pearson correlation (coefficients $=r$ ) analysis showed significant inverse correlations between tHcy $(r=-0.43 ; r=$ $-0.43)$, triglycerides $(r=-0.28 ; r=-0.18)$ creatinine $(r=$ $-0.35 ; r=-0.32$ ) and folate (all $p<0.001$ ) and Cbl (all $p$ $<0.001)$. Creatinine $(r=0.5)$ and triglycerides $(r=0.21)$ correlated positively with tHcy (both $p<0.001$ ). Furthermore significant positive correlations were present between tHcy and BMI $(r=0.44 ; p<0.001)$ and systolic BP $(r=0.14$; $p=0.03)$. Negative correlation was observed between BMI and folate $(r=-0.27)$ and $\mathrm{Cbl}(r=-0.28)$ concentrations (both $p<0.001$ ). Additionally, lower folate correlated with higher diastolic BP $(r=-0.17 ; p=0.01)$. Serum cholesterol and individual or first-degree relative history of CVD were not significantly related to tHcy concentrations.

Table 4. Multivariate analyses for predictors of tHcy concentration in participants $>5$ years and $\leq 5$ years, respectively

\begin{tabular}{lcc}
\hline & $\begin{array}{c}\text { Standardized } \\
\text { coefficient }\end{array}$ & Significance \\
\hline Final regression model for participants & & \\
$\quad>5$ years of age* $\left(\mathrm{R}^{2}=0.35\right)$ & & \\
MTHFR 1793A allele & 0.19 & $p=0.005$ \\
Age & 0.19 & $p=0.018$ \\
Folate & -0.34 & $p=0.004$ \\
Cbl & -0.21 & $p<0.0001$ \\
Final regression model for participants & & \\
$\quad \leq 5$ years of age $\dagger\left(\mathrm{R}^{2}=0.26\right)$ & & \\
$\quad$ Cbl & -0.44 & $p<0.0001$ \\
Folate & -0.21 & $p=0.026$ \\
\hline
\end{tabular}

* Not significant: gender, ethnic background, family history of CVD, categories for sports activities, menstruation, $\mathrm{BP}, \mathrm{BMI}$, cholesterol, triglycerides, creatinine, MTHFR 677C $>$ T, MTHFR 677T/1298C, MTHFR 1298 A $>$ C.

$\dagger$ Not significant: gender, ethnic background, family history of CVD, BP, BMI, cholesterol, triglycerides, creatinine, MTHFR 677C $>$ T, MTHFR 677T/ 1298C, MTHFR 1298 A >C, MTHFR 1793G $>$ A.

\section{DISCUSSION}

Hyperhomocysteinemia is a relevant issue concerning the risk of premature vasculopathy in children; tHcy concentrations exceeding the $95^{\text {th }}$ age percentile are related to a 4-fold increased risk for ischemic cerebrovascular disease (5). The most important results of our study are the increase of tHcy concentrations with age, the inverse correlation of tHcy with folate and $\mathrm{Cbl}$ concentrations and the absence of gender differences for tHcy, folate and $\mathrm{Cbl}$ concentrations. Furthermore tHcy was higher in carriers of the MTHFR 677T or the MTHFR 1793A allele. tHcy was significantly correlated with creatinine, triglycerides, BMI and systolic BP.

Until now a limited number of studies addressed tHcy concentrations (12-14); tHcy, folate and Cbl concentrations $(13,16,17)$ and the impact of the MTHFR $677 \mathrm{C}>\mathrm{T}$ polymorphism on tHcy (17-19) in healthy children and adolescents. Concerning mean tHcy, folate, $\mathrm{Cbl}$ and prevalence of the MTHFR 677TT genotype the most substantial similarity exists between a Dutch sample of 234 children $(0-19 \mathrm{y})$ and our data (17). Likewise mean tHcy concentrations (males: 9.4, females $8.9 \mu \mathrm{mol} / \mathrm{L}$ ) in Slovak adolescents (mean age 14.7 y) were rather similar to our data for this age group (mean $8.6 \mu \mathrm{mol} /$ L). Comparison between 647 scholars from Belgium and our population reveals nonsystematic differences: the $95^{\text {th }}$ percentile was lower in children younger than $14 \mathrm{y}$ (maximum difference $1.7 \mu \mathrm{mol} / \mathrm{L}$ ) but higher (maximum difference 2.4 $\mu \mathrm{mol} / \mathrm{L}$ ) in adolescents from Belgium (13). The $95^{\text {th }}$ percentile and the mean tHcy concentration, respectively, were lower than in our sample in two large studies from the US including 13- to 14-y-old (12) and 12- to 19-y-old (20) non-Hispanic Whites. In contrast, in 127 French Canadians (age 2-18.8 y), both the $95^{\text {th }}$ percentile for tHcy $(14 \mu \mathrm{mol} / \mathrm{L})$ as well as the prevalence of the MTHFR 677TT genotype (17.3\%) (18) were higher than both in our study and the Dutch sample (17). In synopsis, the heterogeneity of results - keeping their limited comparability in mind - supports the concept that ethnic background probably mediated by prevalence of genetic polymorphisms, environment and dietary habits determines tHcy concentrations in healthy children and adolescents.

In contrast to the variety in absolute tHcy concentrations, the increase of tHcy with age has consistently been shown $(13,14,20)$ and our data clearly confirm this observation. The increase of tHcy with age is explicable by the increase in muscle mass during growth resulting in a proportional rise of creatine requirements $(13,14,20)$. Creatine is synthesized from guanidinoacetate by the enzyme guanidinoacetate methyltransferase and this reaction is the overriding consumer of methyl groups provided by S-adenosylmethionine (21). Additionally it has been shown by others $(13,17)$ and in our study that folate and $\mathrm{Cbl}$ concentrations decline with age, probably due to changes in dietary habits and lifestyle in adolescents $(8,13)$, and this process aggravates the increase in tHcy concentrations.

The relationship between gender and tHcy concentrations seems more complex. In our investigation as well as in studies from Spain ( $n=195,2$ mo to 18 y) (14), the US ( $n=1137$, 5-17 y) (22) and the Netherlands $(n=234,0-19$ y) (17) 
including children and adolescents with a wide age distribution, gender differences for tHcy were not assessable. In contrast, in two large samples $(n=1402$ and $n=3524$ respectively) of adolescents (12-15 y, 16-19 y (20) and 13-14 y (12)), tHcy was higher in males compared with females. The most important differences between our study and others proving no gender differences and studies clearly indicating gender differences seem to be sample size and age distribution. Gender differences may not be detectable in smaller samples including only a limited number of postpubertal children, and this is one of the limitations of our study. Another important variable is the insufficient definition of pubertal development by age. Gender differences of tHcy concentrations occur in postpubertal individuals $(13,16)$. The higher tHcy concentrations in males have in this sense been attributed to the greater increase of muscle mass resulting in greater requirements for creatine and hormonal effects which have not been characterized in detail (13). The divergent findings concerning gender differences may therefore reflect heterogeneous distributions of pubertal stages and muscle mass development in different populations regardless of similar age. We see a clear limitation of our study and others in the selection of participants according to age without clear characterization of pubertal stage and muscle mass. The insight into the phenomenon of gender differences of tHcy concentrations seems to be limited in populations selected by age in a cross sectional design. Probably longitudinal studies would be more useful.

Folate and $\mathrm{Cbl}$ are determinants of tHcy concentrations $(8,17)$, but the question of their relation to tHcy gender differences cannot be answered sufficiently at present because the limited number of studies addressing this issue show divergent results. In a Taiwanese sample $(n=1,235 ; 12-15$ y), males had higher tHcy accompanied by lower folate and $\mathrm{Cbl}$ concentrations (16). In contrast, in Belgian adolescents (>15 y) males had higher tHcy concentrations without gender differences for folate and $\mathrm{Cbl}$ (13).

Besides age and gender, polymorphisms in the MTHFR gene are known to interfere with tHcy concentrations. The prevalence of the MTHFR 677TT genotype in our sample corresponds to data from other regions in Middle Europe $(23,24)$ In our sample, as with adults $(6,25)$, tHcy was significantly higher and folate significantly lower in MTHFR 677TT homozygotes, but in contrast, folate and tHcy concentrations were within age specific reference ranges. We additionally investigated whether the effect of the MTHFR 677TT genotype increased with low folate (26) or Cbl concentrations, but in our group these interactions were not present. Our finding of normal tHcy in MTHFR 677TT homozygotes is supported by other studies conducted in pediatric populations $(17,19,27)$. Even though the interpretation of these results is in part limited by small sample sizes (27) or low prevalence of the MTHFR 677TT genotype (19), they are suggestive of a generally weaker influence of the genotype in children and adolescents possessing sufficient folate stores. But the data pool addressing this question is extremely small at present.

The compound heterozygous MTHFR 677T/1298C genotype is only weakly related to mild hyperhomocysteinemia in adult renal replacement patients (28). In children this relation seems to be of even less relevance. In Spanish pediatric recipients of renal transplants (29) as well as in our population, the MTHFR 677T/1298C genotype was not a significant predictor of tHcy plasma levels. For the homozygous MTHFR 1298CC genotype we found no significant impact on tHcy, folate or $\mathrm{Cbl}$ concentrations, which is in line with results in adults (2).

Data on the prevalence and significance of the recently described MTHFR $1793 \mathrm{G}>\mathrm{A}$ polymorphism are sparse at present (10-12). In our sample, this polymorphism was rare with an allele frequency of 0.04 for the mutated allele. Interestingly, the 2 probands with the MTHFR 1793 AA genotype had tHcy concentrations below the $<3^{\text {rd }}$ and $<10^{\text {th }}$ percentile respectively, but Bonferroni corrected subgroup analysis of wild type versus mutated genotypes revealed significantly higher tHcy in carriers of the mutated allele(s). By reason of the low frequency for the mutated allele and deviation from Hardy Weinberg expectations, our study cannot contribute data to the concept that the MTHFR 1793AA genotype might be "protective" with respect to hyperhomocysteinemia as has been discussed by others (11).

Lifestyle factors have been shown to interact with tHcy concentrations. Physical activity is related to lower tHcy concentrations in healthy and diabetic adults $(30,31)$. In contrast in our study, hours of sports activities per week in school children were not related to tHcy concentrations. We hypothesize that during childhood the number of hours of sports activities may not sufficiently reflect the physical activity a child performs and, therefore, we see a clear limitation in the interpretation of this result.

In our study population, BMI and triglycerides were significantly associated with elevated tHcy, low folate and Cbl. Folate and $\mathrm{Cbl}$ are significant predictors for tHcy concentrations as has also been shown by others $(8,17)$. Like in adults, tHcy correlates with systolic BP (30). This relation may reflect vascular changes induced by an impairment of nitric oxide synthesis induced by tHcy (32) or dietary habits associated with higher fat intake and BMI, two parameters known to be associated with higher BP (33). Furthermore tHcy correlates with creatinine, reflecting the relation of both parameters to muscle mass (33).

In conclusion, tHcy increases while folate and $\mathrm{Cbl}$ concentrations decrease with age. Gender differences for these parameters are not generally present in children. Folate and $\mathrm{Cbl}$ concentrations are the main determinants of tHcy concentrations. The MTHFR 677TT genotype and the MTHFR 1793A allele are associated with higher tHcy but not with hyperhomocysteinemia. Folate, Cbl, triglycerides and BMI correlate significantly with tHcy concentrations in children and adolescents. Therefore, a change in dietary habits may be a therapeutic target in lowering tHcy in children and adolescents.

Acknowledgments. The authors thank the staff of the Department of Anaesthesia for assistance in ascertaining the patients, and Corinna Eberle for her skilful technical assistance. We gratefully acknowledge the support provided by 
Claudia Kiener, Helmut Brehl and SHS Clinical Nutrition Heilbronn.

\section{REFERENCES}

1. Finkelstein JD 2000 Pathways and regulation of homocysteine metabolism in mammals. Semin Thromb Hemost 26:219-225

2. van der Put NM, Gabreels F, Stevens EM, Smeitink JA, Trijbels FJ, Eskes TK, van den Heuvel LP, Blom HJ 1998 A second common mutation in the methylenetetrahydrofolate reductase gene: an additional risk factor for neural-tube defects? Am J Hum Genet 62:1044-1051

3. Prengler M, Sturt N, Krywawych S, Surtees R, Liesner R, Kirkham F 2001 Homozygous thermolabile variant of the methylenetetrahydrofolate reductase gene: a potential risk factor for hyperhomocysteinaemia, CVD, and stroke in childhood. Dev Med Child Neurol 43:220-225

4. Ho PI, Ashline D, Dhitavat S, Ortiz D, Collins SC, Shea TB, Rogers E 2003 Folate deprivation induces neurodegeneration: roles of oxidative stress and increased homocysteine. Neurobiol Dis 14:32-42

5. van Beynum IM, Smeitink JA, den Heijer M, te Poele Pothoff MT, Blom HJ 1999 Hyperhomocysteinemia: a risk factor for ischemic stroke in children. Circulation 99:2070-2072

6. Födinger M, Buchmayer H, Sunder-Plassmann G 1999 Molecular genetics of homocysteine metabolism. Miner Electrolyte Metab 25:269-278

7. Stanger O, Herrmann W, Pietrzik K, Fowler B, Geisel J, Dierkes J, Weger M 2003 DACH-LIGA homocystein (German, Austrian and Swiss homocysteine society) consensus paper on the rational clinical use of homocysteine, folic acid and B-vitamins in cardiovascular and thrombotic diseases: guidelines and recommendations. Clin Chem Lab Med 41:1392-1403

8. Schneede J, Refsum H, Ueland PM 2000 Biological and environmental determinants of plasma homocysteine. Semin Thromb Hemost 26:263-279

9. Rady PL, Szucs S, Grady J, Hudnall SD, Kellner LH, Nitowsky H, Tyring SK, Matalon RK 2002 Genetic polymorphisms of methylenetetrahydrofolate reductase (MTHFR) and methionine synthase reductase (MTRR) in ethnic populations in Texas; a report of a novel MTHFR polymorphic site, G1793A. Am J Med Genet 107:162-168

10. Winkelmayer WC, Sunder-Plassmann G, Huber A, Födinger M 2004 Patterns of co-occurrence of three single nucleotide polymorphisms of the 5,10-methylenetetrahydrofolate reductase gene in kidney transplant recipients. Eur J Clin Invest 34:613-618

11. Winkelmayer WC, Huber A, Wagner OF, Hörl WH, Sunder-Plassmann G, Födinger M 2005 Associations between MTHFR 1793G >A and plasma total homocysteine, folate, and vitamin B in kidney transplant recipients. Kidney Int 67:1980-1985

12. Osganian SK, Stampfer MJ, Spiegelman D, Rimm E, Cutler JA, Feldman HA, Montgomery DH, Webber LS, Lytle LA, Bausserman L, Nader PR 1999 Distribution of and factors associated with serum homocysteine levels in children. Child and adolescent trial for cardiovascular health. JAMA 281:1189-1196

13. De Laet C, Wautrecht JC, Brasseur D, Dramaix M, Boeynaems JM, Decuyper J, Kahn A 1999 Plasma homocysteine concentration in a Belgian school-age population. Am J Clin Nutr 69:968-972

14. Vilaseca MA, Moyano D, Ferrer I, Artuch R 1997 Total homocysteine in pediatric patients. Clin Chem 43:690-692

15. Huemer M, Ausserer B, Graninger G, Hubmann M, Huemer C, Schlachter K, Tscharre A, Ulmer H, Simma B 2005 Hyperhomocysteinemia in children treated with antiepileptic drugs is normalized by folic acid supplementation. Epilepsia 46:1677-1683

16. Shen MH, Chu NF, Wu DM, Chang JB 2002 Plasma homocyst(e)ine, folate and vitamin $\mathrm{B}(12)$ levels among school children in Taiwan: The Taipei Children Heart Study. Clin Biochem 35:495-498

17. van Beynum IM, den Heijer M, Thomas CM, Afman L, Oppenraay-van Emmerzaal D, Blom HJ 2005 Total homocysteine and its predictors in Dutch children. Am J Clin Nutr 81:1110-1116
18. Delvin EE, Rozen R, Merouani A, Genest J Jr., Lambert M 2000 Influence of methylenetetrahydrofolate reductase genotype, age, vitamin B-12, and folate status on plasma homocysteine in children. Am J Clin Nutr 72:1469-1473

19. Raslova K, Bederova A, Gasparovic J, Blazicek P, Smolkova B 2000 Effect of diet and $677 \mathrm{C}->\mathrm{T} 5,10$-methylenetetrahydrofolate reductase genotypes on plasma homocyst(e)ine concentrations in slovak adolescent population. Physiol Res 49:651-658

20. Jacques PF, Rosenberg IH, Rogers G, Selhub J, Bowman BA, Gunter EW, Wright JD, Johnson CD 1999 Serum total homocysteine concentrations in adolescent and adult Americans: results from the third National Health and Nutrition Examination Survey. Am J Clin Nutr 69:482-489

21. Rauh M, Verwied S, Knerr I, Dorr HG, Sonnichsen A, Koletzko B 2001 Homocysteine concentrations in a German cohort of 500 individuals: reference ranges and determinants of plasma levels in healthy children and their parents. Amino Acids 20:409-418

22. Greenlund KJ, Srinivasan SR, Xu JH, Dalferes E Jr., Myers L, Pickoff A, Berenson GS 1999 Plasma homocysteine distribution and its association with parental history of coronary artery disease in black and white children: the Bogalusa Heart Study. Circulation 99:2144-2149

23. Wilcken B, Bamforth F, Li Z, Zhu H, Ritvanen A, Renlund M, Stoll C, Alembik Y, Dott B, Czeizel AE, Gelman-Kohan Z, Scarano G, Bianca S, Ettore G, Tenconi R, Bellato S, Scala I, Mutchinick OM, Lopez MA, de Walle H, Hofstra R, Joutchenko L, Kavteladze L, Bermejo E, Martinez-Frias ML, Gallagher M, Erickson JD, Vollset SE, Mastroiacovo P, Andria G, Botto LD 2003 Geographical and ethnic variation of the $677 \mathrm{C}>\mathrm{T}$ allele of 5,10 methylenetetrahydrofolate reductase (MTHFR) findings from over 7000 newborns from 16 areas world wide. J Med Genet 40:619-625

24. Botto LD, Yang Q 2000 5,10-Methylenetetrahydrofolate reductase gene variants and congenital anomalies: a HuGE review. Am J Epidemiol 151:862-877

25. Blom HJ 2000 Genetic determinants of hyperhomocysteinaemia: the roles of cystathionine beta-synthase and 5,10-methylenetetrahydrofolate reductase. Eur J Pediatr 159:S208-S212

26. Papoutsakis C, Yiannakouris N, Manios Y, Papaconstantinou E, Magkos F, Schulpis $\mathrm{KH}$, Zampelas A, Matalas AL 2005 Plasma homocysteine concentrations in Greek children are influenced by an interaction between the methylenetetrahydrofolate reductase C677T genotype and folate status. J Nutr 135:383-388

27. Wiltshire E, Thomas DW, Baghurst P, Couper J 2001 Reduced total plasma homocyst(e)ine in children and adolescents with type 1 diabetes. J Pediatr 138:888893

28. Födinger M, Buchmayer H, Heinz G, Papagiannopoulos M, Kletzmayr J, RasoulRockenschaub S, Horl WH, Sunder-Plassmann G 2000 Effect of MTHFR 1298A->C and MTHFR 677C->T genotypes on total homocysteine, folate, and vitamin $\mathrm{B}(12)$ plasma concentrations in kdiney graft recipients. J Am Soc Nephrol 11:1918-1925

29. Aldamiz-Echevarria L, Sanjurjo P, Vallo A, Aquino L, Perez-Nanclares G, Gimeno P, Rueda M, Ruiz I, Urreizti R, Rodriguez-Soriano J 2002 Hyperhomocysteinemia in children with renal transplants. Pediatr Nephrol 17:718-723

30. Nygard O, Vollset SE, Refsum H, Stensvold I, Tverdal A, Nordrehaug JE, Ueland M, Kvale G 1995 Total plasma homocysteine and cardiovascular risk profile. The Hordaland Homocysteine Study. JAMA 274:1526-1533

31. Hellgren M, Melander A, Ostgren CJ, Rastam L, Lindblad U 2005 Inverse association between plasma homocysteine, sulphonylurea exposure and physical activity: a community-based sample of type 2 diabetes patients in the Skaraborg hypertension and diabetes project. Diabetes Obes Metab 7:421-429

32. Doshi S, McDowell I, Goodfellow J, Stabler S, Böger R, Allen R, Newcombe R, Lewis M, Moat S 2005 Relationship between S-adenosylmethionine, S-adenosylhomocysteine, asymmetric dimethylarginine, and endothelial function in healthy human subjects during experimental hyper- and hypohomocysteinemia. Metabolism 54:351360

33. Bjorke Monsen AL, Ueland PM 2003 Homocystine and methylmalonic acid in diagnosis and risk assessment from infancy to adolescence. Am J Clin Nutr $78: 7-21$ 